\title{
O TRATAMENTO DADO AO ERRO EM CLASSES DE RECUPERAÇÃO INTENSIVA: O CASO DE UM PROFESSOR DE MATEMÁTICA
}

Ana Cristina da Silva. Ambrosio, Leny Rodrigues Martins Teixeira

PPGE/Universidade Estadual Paulista - UNESP. E-mail: anacrisambrosio@hotmail.com

\section{RESUMO}

O objetivo deste trabalho é apresentar e analisar situações de aprendizagem em que o professor constata o erro do aluno e qual o tratamento dado ao erro. As situações apresentadas foram observadas em uma classe de Recuperação Intensiva do Ensino Fundamental ciclo II, durante as aulas de matemática, entre os meses de agosto a novembro de 2012. Teoricamente, partimos do pressuposto de que o erro é inerente ao processo de aprender, um indicador do que o aluno sabe e de como ele compreende determinado conteúdo, sendo um importante instrumento para o professor analisá-lo e assim repensar sua prática docente. Os resultados mostram que uma prática voltada ao diálogo e ao questionamento do aluno em detrimento da mera transmissão de conteúdo facilita a compreensão significativa do conhecimento matemático.

Palavras-chave: Ensino de Matemática; Análise de erros; Recuperação Intensiva.

\section{INTRODUÇÃO}

Na sociedade em que vivemos, errar, no geral, é visto como algo que deve ser evitado, e que quando acontece, quase sempre não é aceito. Essa visão amplamente socializada, dando esse caráter negativo ao erro tem influenciado a escola, como afirma Lorenzato (2008):

\begin{abstract}
"Socialmente, a palavra erro sempre teve uma conotação negativa referindo-se a algo ruim que categoricamente deveria ser evitado. Aqueles que cometessem algum erro seriam penalizados. Essa tradição social influenciou nos paradigmas educacionais, os quais, por sua vez, interferiram na maneira de a escola interpretar os erros dos alunos, referentes à aquisição de conhecimentos." (Lorenzato, 2008, p. 49)
\end{abstract}

Por muito tempo, imperou na educação a ideia de que quando o aluno sabe, acerta, quando não sabe, erra, sem levar em conta o pensamento que o levou a produzir aquela resposta. Felizmente, a partir da segunda metade do século XX, essa perspectiva começou a ser superada, e aos poucos, pesquisadores da área educacional e professores passaram a enxergar o erro do aluno como algo inerente ao processo de aprender.

No próprio desenvolvimento da Ciência, os estudiosos sempre se depararam com situações de dúvidas e inquietações, e por inúmeras vezes erraram antes de chegar à conclusão correta. Por que então, quando o aluno está aprendendo algo novo, que possivelmente demorou anos para ser 
entendido pelos pesquisadores, alguns professores insistem em considerar o erro como algo negativo, um mero indicador de que o aluno não entendeu nada?

Neste artigo, apresentamos um caso específico de constatação do erro por um professor de matemática. Os dados obtidos referem-se à pesquisa de mestrado em desenvolvimento intitulada "A Recuperação Intensiva do Ensino Fundamental ciclo II: uma análise da prática pedagógica do professor de matemática", na qual analisamos a prática de professores de matemática atuantes em classes de Recuperação Intensiva, e que está devidamente registrada e aprovada pelo Comitê de Ética em Pesquisa, sob o número de protocolo 05079612.2.0000.5402.

O projeto da Recuperação Intensiva foi instituído pela Secretaria Estadual de Educação do Estado de São Paulo no ano de 2012, com o objetivo de atender alunos com maiores dificuldades de aprendizagem, formando classes específicas para estes alunos, nas quais os professores deveriam trabalhar de forma diferenciada, possibilitando que no ano seguinte os alunos retornem para as salas regulares.

Na dissertação de mestrado, optamos por analisar a prática do professor de matemática nestas salas, uma vez que no Estado de São Paulo os projetos de recuperação são essenciais para garantir uma boa qualidade educacional, visto que desde o ano de 1998 o Estado adota o regime de Progressão Continuada. Tal regime aboliu a organização do currículo em séries, instituindo os ciclos, e em consequência a ausência de reprovação. Deste modo, em um sistema de classes tão heterogêneas, com alunos em diferentes níveis de conhecimento, o que, na maioria das vezes, impossibilita um trabalho individualizado com os alunos, a recuperação ou reforço escolar constitui um mecanismo essencial para garantir que, ao final do ciclo, todos os alunos possam alcançar níveis melhores de aprendizado.

No presente texto, apresentamos duas situações de aprendizagem observadas durante as aulas de um professor de matemática de 70 ano de Recuperação Intensiva. Estas situações demonstram como o professor reage frente aos erros cometidos por seus alunos na resolução das questões propostas, e evidenciam a necessidade de diálogo professor-aluno, e como isso pode auxiliar no aprendizado. A observação nas aulas deste professor ocorreram entre os meses de agosto a novembro de 2012.

O tema "análise de erros" torna-se importante, pois compreendemos que as aulas de recuperação são o momento ideal para o aluno com dificuldades (re)construir o conceito matemático que não foi aprendido de maneira correta, recebendo tratamento individualizado, no qual o professor deve estar atento às respostas dos alunos, ouvindo-o, para desvelar seus 
pensamentos e motivos (Lorenzato, 2008), garantindo ao aluno progressão continuada com efetiva aprendizagem.

\section{ANÁLISE DE ERROS NO PROCESSO ENSINO-APRENDIZAGEM}

A forma de se encarar uma resposta dada pelo aluno está intimamente relacionada à crença do professor sobre a avaliação. Tradicionalmente, a avaliação é meramente quantitativa, medindo a quantidade de respostas certas e erradas, sem considerar o raciocínio efetuado pelo aluno para chegar àquela conclusão. Nesta perspectiva, a avaliação é um exame, mero instrumento de verificação e classificação, na qual se atribui um número às respostas dadas pelos alunos em determinada prova. Deste modo, a "avaliação" ocorre no final, e não durante processo ensino-aprendizagem, pouco contribuindo com a construção de conhecimento do aluno.

Neste modelo de avaliação, o erro é considerado um indicador do fracasso do aluno, mostrando que ele não aprendeu o que deveria, e deve ser substituído pelo acerto, sem considerar o pensamento que levou o educando àquela resposta, como nos mostra Pinto (2000):

"Em geral, o erro era observado pelo professor como um indicador do mau desempenho do aluno, sem jamais ser utilizado para o redimensionamento do ensino. O que permeava o ensino era uma "pedagogia da resposta" em que o erro era o sintoma visível do fracasso do aluno, assim como o acerto era o sinal mais evidente de seu sucesso." (Pinto, 2000, p. 8)

Este modelo, de exame quantitativo, aos poucos vem perdendo sentido na escola, principalmente pelas indicações legais que surgiram, em especial a Lei de Diretrizes e Bases da Educação Nacional (Lei 9.394/96), que afirma que a avaliação deve ser contínua, devendo prevalecer os aspectos qualitativos aos quantitativos. Entretanto, esta nova forma de avaliação requer uma nova concepção do erro dos alunos, como afirma Tanus(2008):

“(...) uma nova perspectiva de avaliação, mais inclusiva, deverá ater-se também a um tratamento diferenciado com o erro do aluno, de modo que este não seja apenas classificado como resposta errada, produto final a ser banido, punido, mas, transformado, superado, considerando o processo de reflexão do aluno como forma de avançar no conhecimento. Assim, a preocupação do professor na avaliação estaria mais centrada no processo da aprendizagem do que no produto final."(Tanus, 2008, p. 56)

O erro então deixa de ser indesejável e meramente punível e passa a ser parte integrante do processo de aprender, revelando o pensamento do aluno, dando pistas ao professor do que aquele educando compreendeu, constituindo-se em um importante momento de aprendizagem 
para o professor, pois possibilita a ele compreender como os alunos se apropriam de um determinado conhecimento matemático (CURY, 2008).

De fato, não é somente considerar o erro, mas compreender o que há por trás da resposta que o aluno deu, pois acertar também não garante que ele aprendeu, como afirma Cury (2008):

“Na análise das respostas dos alunos, o importante não é o acerto ou o erro em si - que são pontuados em uma prova de avaliação da aprendizagem -, mas as formas de se apropriar de um determinado conhecimento, que emergem na produção escrita e que podem evidenciar dificuldades de aprendizagem." (Cury, 2008, p. 63)

Desta forma, a partir da análise das respostas dos alunos o professor pode repensar sua maneira de ensinar, compreendendo melhor como o educando se apropria dos conceitos que está aprendendo, o que se torna um facilitador no processo ensino-aprendizagem.

Consideramos que o erro não é casual, ele é parte do processo de construção do conhecimento (Teixeira, 2004) e portanto precisa ser levado em conta pelo professor, pois pode mostrar como o aluno aprende e compreende determinado conteúdo. Para a análise das falas dos professores nos apoiamos principalmente na posição defendida por Lorenzato(2008):

"Ao professor compete, primeiramente, dispensar constante atenção para constatar o erro, lembrando que acerto pode camuflar erro. É importante diagnosticar como o erro se deu, sem o que será impossível encontrar a(s) causa(s) dele. Nessa fase, é fundamental ouvir o aluno, conversar com ele com o objetivo de desvelar seu pensamento e seus motivos. Feita a diagnose, convém propor ao aluno uma ou mais situações com as quais ele possa perceber a incoerência de suas respostas ou posições. Auxiliando o aluno a descobrir novas alternativas, podemos esperar que ele reformule seus conceitos, corrija o erro e, assim, evolua." (Lorenzato, 2008, p. 50)

Acreditamos, ainda, que o fato de as classes de recuperação contarem com uma quantidade menor de alunos (no máximo 20 alunos por turma) do que as classes regulares colabora para que o professor dê um atendimento individualizado aos seus alunos, podendo ouvilos com maior interesse, analisando suas respostas, o que culminaria em melhor aprendizado.

\section{O TRATAMENTO DADO AO ERRO}

No decorrer das observações foram identificadas inúmeras situações em que o professor constatou erros de seus alunos. De modo geral, ele manteve a forma de tratamento dado ao erro durante o trabalho desenvolvido. Para ilustrar a prática selecionamos dois registros das situações observadas. Para assegurar o sigilo do professor, o identificaremos como Professor A. 


\section{Professor A}

Situação 1 - Em uma aula sobre números inteiros, o professor dá a seguinte atividade:

"Registre as operações e o saldo utilizando números com sinais.

a) o saldo após um crédito de 170 reais e um débito de 110 reais"

Um aluno leva o caderno para o professor corrigir e logo no item "a" a resposta está errada, o professor então fala para o aluno "preste atenção, o crédito é 170 e o débito 110, quem é maior?", o aluno responde "o crédito", o professor "se entra 170 e sai 110, sobra uma dívida ou sobra dinheiro?", o aluno responde "dinheiro", e o professor completa "então, você colocou o saldo devedor, é credor." E o aluno volta ao seu lugar para tentar resolver a questão.

Situação 2 - Em uma aula sobre probabilidade, depois da explicação na lousa, o professor passa para os alunos o seguinte exercício:

“A tabela abaixo representa a produção de um determinado carro popular com três tipos de motorização e três tipos de cores.

\begin{tabular}{|l|l|l|l|}
\cline { 2 - 4 } \multicolumn{1}{c|}{} & Preto & Branco & Vermelho \\
\hline motor 1.0 & 25 & 30 & 18 \\
\hline motor 1.4 & 17 & 13 & 13 \\
\hline motor 1.6 & 8 & 7 & 19 \\
\hline total & 50 & 50 & 50 \\
\hline
\end{tabular}

Item f) Escolhendo ao acaso um veículo qualquer, qual é a chance de que seja da cor branca?"

Um aluno questiona o professor se a resposta do item $f$ é $1 / 3$. O professor pergunta ao aluno "mas por que você escreveu 1/3?", o aluno explica que é porque considera uma cor em três, o professor então explica "você tem que considerar na verdade a quantidade de veículos, a quantidade de brancos e o total", o aluno então responde "50/150" e o professor completa "neste caso coincidentemente vai dar $1 / 3$, depois de simplificar".

Na situação 1, o professor inicia o diálogo já dizendo que o aluno está errado, sem antes questionar o motivo que o levou a dar àquela resposta. Isto de certa forma impede que a criança verbalize seu pensamento e o professor não sabe o que ela pensou. Entretanto, ao questionar o aluno, o professor o leva a conclusão correta, mostrando porque ele errou.

A situação 2 nos chamou a atenção pelo fato de o aluno ter dado a resposta correta, e o professor o questionou "mas por que você escreveu 1/3?". Esta pergunta foi essencial para o professor compreender o que o aluno tinha pensado, e o ajudar a compreender da maneira correta. Esta situação em especial demonstra bem a afirmação de Cury (2008), de que nem 
sempre o acerto é garantia de que o aluno aprendeu, e a importância de se questionar o aluno, pois ele tinha dado a resposta correta, mas não tinha utilizado o raciocínio adequado.

A observação das aulas deste professor mostrou que mesmo durante a explicação do conteúdo ele sempre iniciava fazendo questionamentos aos alunos, e de acordo com as respostas direcionava sua fala. Na constatação do erro, mais uma vez questionava o aluno, sem responder diretamente a dúvida que o aluno apresentava, o que caracteriza uma prática mais inclusiva, voltada para a compreensão do processo de aprendizagem do aluno, fato essencial para a correção do erro. Apesar de adotar tais procedimentos de forma intuitiva, o caminho adotado por este professor poderia ser muito mais produtivo para os alunos se fosse trabalhado de forma mais sistemática.

Este modo de ensinar é considerado pelos pesquisadores como um excelente facilitador para a compreensão significativa por parte dos alunos, pois não apresenta a Matemática como um conjunto de regras, e sim como um processo.

\section{CONSIDERAÇÕES FINAIS}

Apresentamos o presente trabalho com o objetivo de analisar as situações de constatação do erro e mostrar que é possível considerá-lo como parte integrante do processo de aprender.

Não houve a pretensão de eleger uma determinada prática docente como certa ou errada, apenas identificar e analisar práticas que demonstraram ser boas alternativas a serem realizadas na sala de Recuperação Intensiva, considerando que é uma sala destinada a alunos com dificuldades de aprendizagem.

Em uma escola cada vez mais inclusiva, preocupada com a aprendizagem de todos os alunos, não cabe mais os modelos tradicionais de avaliação e tratamento do erro. O professor que considera o erro como indicador do fracasso do aluno e o acerto como garantia de aprendizagem precisa repensar sua prática e aproximá-la da atual realidade da escola e dos estudos sobre os processos cognitivos envolvidos na aprendizagem.

Grande parte do envolvimento e interesse do aluno em seu próprio processo de aprender está nas mãos do professor, que decide qual o melhor caminho a seguir entre a dúvida e o conhecimento. Se considerar o pensamento do aluno, ouvi-lo e deixar que ele conjecture a sua maneira, ao invés de impor um modo de pensar já estabelecido, o professor dá aos aprendizes a oportunidade de construir o próprio conhecimento, que será muito mais significativo e duradouro. 
Afinal, não é só errando que se aprende, mas compreendendo o erro é que se constrói conhecimento.

\section{REFERÊNCIAS}

CURY, Helena Noronha. Erros em soluções de problemas de cálculo diferencial e integral: análise, classificação e tentativas de superação. Porto Alegre: PUCRS, Instituto de Matemática. Relatório de pesquisa, 1990.

CURY, Helena Noronha. Análise de erros: o que podemos aprender com as respostas dos alunos. Belo Horizonte: Autêntica, 2008.

LORENZATO, Sergio. Para aprender Matemática. 2 Ed. Campinas, SP: Autores Associados, 2008. PINTO, Neuza Bertoni. $O$ erro como estratégia didática: Estudo do erro no ensino da matemática elementar.Campinas, SP: Papirus, 2000.

TANUS, Vera Lúcia Fernandes Aragão. 0 tratamento dado ao erro no processo ensinoaprendizagem da Matemática, por professores do Ensino Fundamental: encontros e desencontros entre concepções e práticas. Dissertação de Mestrado. Cuiabá, Universidade Federal de Mato Grosso, 2008.

TEIXEIRA, Leny Rodrigues Martins. Dificuldades e Erros na Aprendizagem da Matemática. Anais do VII Encontro Paulista de Educação Matemática: VII EPEM. São Paulo: SBEM/SBEM-SP, 2004. 